\title{
Brachial plexus and radicular neurography in relation to cortical evoked responses
}

\author{
J . S I I V O LA, V. V. M Y L L Y L Ä, I.S U L G, \\ A N D E. H O K K A N E N \\ From the Departments of Neurology and Clinical Neurophysiology, Oulu University Central Hospital, \\ Oulu, Finland
}

SUMMARY An application of somatosensory potential recording suitable for clinical neurodiagnostics is described. Evoked responses were recorded with surface electrodes at four levels between wrist and scalp: Erb's point, seventh cervical spine, inion, and the somatosensory area of the scalp. The normal latency and latency difference values based on 16 healthy subjects are presented as well as those of four examples of pathological cases with lesions at various levels in the nervous system. The method presented offers novel possibilities for solving problems of differential diagnosis, especially at the level of the brachial plexus.

Cerebral and spinal somatosensory evoked responses have been studied intensively in recent years, particularly in the electrophysiological investigation of various diseases of the nervous system.

Three principal recording techniques can be used in man: (1) the surface electrode technique, used by most investigators, which is noninvasive and safe; (2) the epidural technique, described by Shimoji et al. $(1971,1972)$ among others; (3) the intrathecal technique, used, for example, by Ertekin (1976, 1978), which is an invasive and rarely applicable method in humans.

In differential diagnosis it is important to record evoked responses at various levels of the nervous system, especially for the accurate evaluation of the site of the lesion. The recording of somatosensory evoked responses of the scalp, for example, only gives information about the conduction of nerve impulses between peripheral stimulation points and the scalp, but it does not localise the actual level of the lesion. Since the somatosensory evoked response may be abnormal, even when the lesion is peripheral-in the brachial plexus, for example-only stimulation and recording from selected levels can give reliable information about the lesion site.

In this paper we review some of the clinical applications of somatosensory evoked responses

Address for reprint requests: Professor E. Hokkanen, Department of Neurology, University of Oulu, SF-90220 Oulu 22, Finland.

Accepted 14 May 1979 with information from four different levels of the nervous system between the wrist and the scalp.

\section{Subjects and methods}

Sixteen healthy volunteers, recruited mostly from laboratory and medical staff, eight males and eight females, between 15 and 52 years of age were studied. These procedures on volunteers and patients had the approval of the hospital ethical committee.

In all 16 control subjects the following recordings were carried out with median nerve stimulation: scalp somatosensory evoked potential (SSEP) and nuchal somatosensory evoked potential (NEP) from inion (Koivikko et al., 1976). In 10 control subjects the evoked responses at the levels of the seventh cervical spine (SEP-Cv7) and Erb's point (P1Br-AP) were also recorded when median and ulnar nerves were stimulated.

Four patients were examined, one each with multiple sclerosis, brain tumour, costoclavicular syndrome, and ulnar entrapment neuropathy.

\section{STIMULATION AND RECORDING}

Square wave electric pulses of $0.30 \mathrm{~ms}$ duration were generated by a stimulator (Disa $13 \mathrm{~K} \mathrm{62}$ ) and delivered at a rate of four per second. The stimulating cathode was approximately $25 \mathrm{~mm}$ proximal to the anode. Stimulus intensity was adjusted to produce twitching of the fingers, movement of a thumb on median nerve stimulation, and of ulnar 
fingers on ulnar nerve stimulation, the subject being instructed to maintain his hand and wrist in a constant position. According to Hume and Cant (1978) stimulus intensity exceeding the limit of slight twitching does not increase the amplitude of the response. Both hands were stimulated separately in all subjects. The stimulation site for control subjects was only on the wrist. The procedure was easy to perform and stimulus intensity, inducing twitch of the fingers, was noticeably beneath the maximal tolerance.

Examinations were made in a sound-attenuating, electrically shielded room. The subjects were in the supine position during the recording and were instructed to minimise the movements of face, eyes, and swallowing.

On the scalp and inion the recordings were carried out with chlorided silverplate-electrodes, as used in routine EEG examination. Scalp electrodes were placed over the right and left central cephalic region (C4, C3, international 10-20 system). The reference point for the inion electrode was on the mid-forehead (Fz) and for the scalp electrode on the ear lobe on the stimulated site. In the cervical recording (Cv7) the same type of silver/silver chloride electrode was placed over the seventh cervical spine; in the brachial plexus examination the recording electrode was at Erb's point, referred to the midline of the forehead.

The input from two recording channels was led through a high impedance differential amplifier with a bandpass of $2 \mathrm{~Hz}-10 \mathrm{kHz}(-3 \mathrm{~dB})$ into an EMG machine (Disa $14 \mathrm{C} \mathrm{12}$ ) and from there into a two-channel signal analyser, HP$5481 \mathrm{~A}$. The analysis of the two recording channels was performed simultaneously (a) from scalp and inion, and (b) from $\mathrm{Cv} 7$ and Erb's point. The resolution of sampling (bin width) was $200 \mu \mathrm{s}$.

Routinely 512 responses were averaged. The EMG was monitored continuously and if the noise increased noticeably-for example, because of muscle artefacts, loosening of electrodes and so on, the averaging was stopped and the error was eliminated. One stimulation period of one nerve took about eight minutes for both hands.

\section{MEASUREMENTS AND ANALYSIS}

The latencies and amplitude of evoked responses were displayed by means of a recorder connected to the signal analyser. The means and standard deviations (SD) were calculated for all the measured parameters and also the ratios of the respective right and left amplitudes (Ad/As).

The nomenclature of the various components in the present work is quite similar to that recommended by Donchin et al. (1977) and used, for
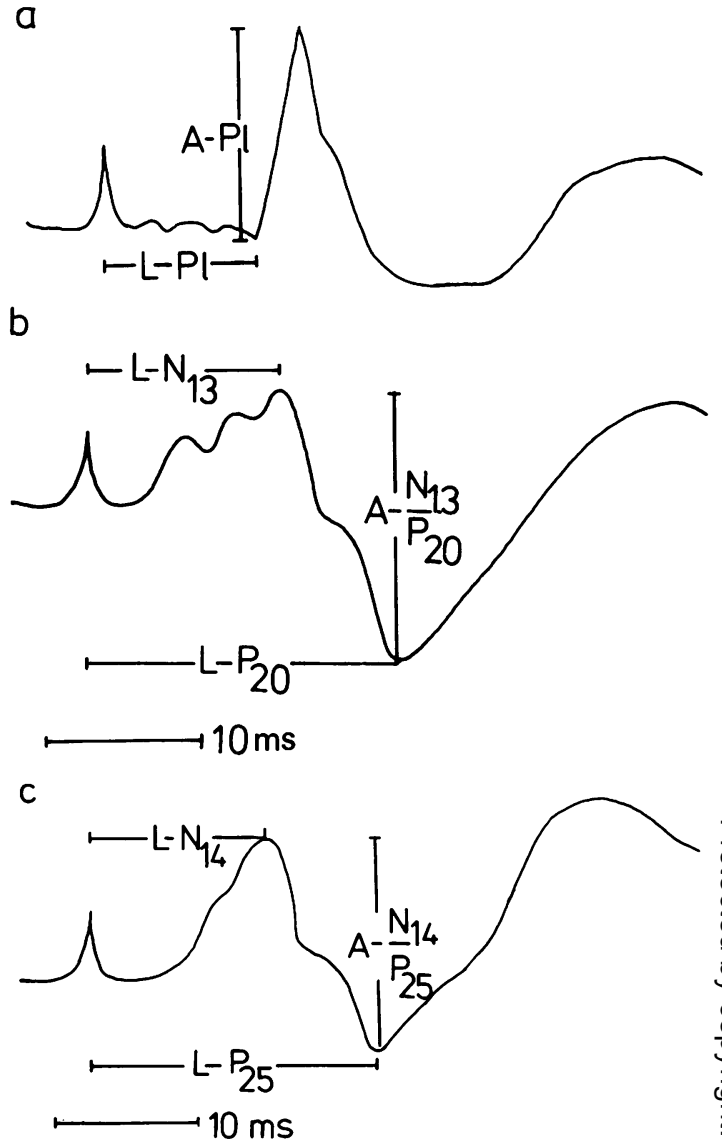

d

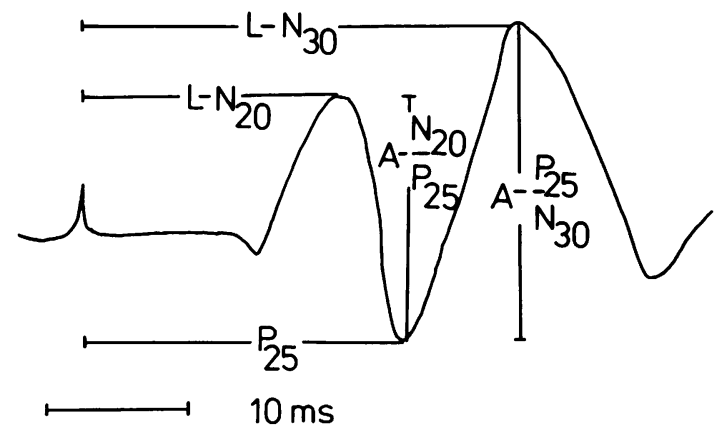

Fig. 1 Diagram of the somatosensory evoked responses (SER) at Erb's point (a), the seventh cervical spine (b), the inion (c), and the scalp (d) evoked by stimulation at the wrist. Both amplitudes $(A)$ and latencies $(L)$ are shown. The first deflection is the stimulus artefact.

example, by Jones (1977): components are identified by their polarity and mean peak latency. The 
Table 1 The latencies (L-P1 and L-N13), amplitudes ( $A-P 1$ and $A-N 13 / P 20)$, conduction velocities from wrist to Erb's point (CV), and the ratios of amplitudes from the right and left side (Ad/As) in control subjects, with means and standard deviations $(S D)$ of all parameters

\begin{tabular}{|c|c|c|c|c|c|c|c|c|}
\hline \multicolumn{5}{|l|}{$P l B r-A P$} & \multicolumn{4}{|l|}{$S E P-C v 7$} \\
\hline $\begin{array}{l}\text { Median } \\
\text { nerve }\end{array}$ & $L-P l(m s)$ & $C V(m / s)$ & $A-P l(\mu V)$ & $A d / A s$ & $L-N 13(m s)$ & $L-P 20(m s)$ & $\begin{array}{l}A-N 13 / P 20 \\
(\mu V)\end{array}$ & $A d / A s$ \\
\hline $\begin{array}{l}\text { Mean } \\
\text { SD } \\
\mathbf{N}\end{array}$ & $\begin{array}{c}8.2 \\
0.5 \\
10\end{array}$ & $\begin{array}{c}7.1 \\
3.0 \\
10\end{array}$ & $\begin{array}{l}6.4 \\
2.5 \\
10\end{array}$ & $\begin{array}{c}0.90 \\
0.11 \\
10\end{array}$ & $\begin{array}{c}12.4 \\
0.6 \\
10\end{array}$ & $\begin{array}{c}20.2 \\
2.5 \\
10\end{array}$ & $\begin{array}{l}4.5 \\
1.1 \\
10\end{array}$ & $\begin{array}{l}0.90 \\
0.11 \\
10\end{array}$ \\
\hline \multicolumn{5}{|l|}{$P l B r-A p$} & \multicolumn{4}{|l|}{$S E P-C v 7$} \\
\hline Ulnar nerve & $L-P l(m s)$ & $C V(m / s)$ & $A-P I(\mu V)$ & $A d / A s$ & $L-N 13(m s)$ & $L-P 20(m s)$ & $\begin{array}{l}A-N 13 / P 20 \\
(\mu V)\end{array}$ & $A d / A s$ \\
\hline $\begin{array}{l}\text { Mean } \\
\text { SD } \\
\mathbf{N}\end{array}$ & $\begin{array}{c}8.8 \\
0.5 \\
10\end{array}$ & $\begin{array}{c}66.0 \\
3.0 \\
10\end{array}$ & $\begin{array}{l}4.0 \\
2.5 \\
10\end{array}$ & $\begin{array}{l}0.95 \\
0.11 \\
10\end{array}$ & $\begin{array}{c}13.4 \\
0.6 \\
10\end{array}$ & $\begin{array}{c}21.5 \\
2.5 \\
10\end{array}$ & $\begin{array}{c}2.6 \\
1.1 \\
10\end{array}$ & $\begin{array}{l}0.85 \\
0.11 \\
10\end{array}$ \\
\hline
\end{tabular}

Stimulation of median and ulnar nerves at the wrist, separately from both hands in 10 patients $(=N)$.

Recordings: Erb's point and seventh cervical s:ine

Reference: mid-forehead (Fz).

number indexes of phases in the scalp and inion recordings are the same as used by most authors. The measurement up to the first negative deflection of SEP was performed up to the peak N13, not to the earlier peaks, since the peak N13 was most frequently the clearest and highest one of the whole deflection in this recording. The landmarks for the measurement are presented in Fig. 1.

\section{Results}

\section{CONTROL SUBJECTS}

In Table 1 the recorded values of the following parameters in 10 control subjects are presented: latency from the median nerve at the wrist to Erb's point $(\mathrm{L}-\mathrm{Pl})$ was $8.2 \pm 0.5 \mathrm{~ms}$, conduction velocity was $76 \mathrm{~m} / \mathrm{s}$, amplitude of action potential (A-Pl) was $6.4 \pm 2.5 \mu \mathrm{V}$, and the ratio of respective amplitudes, Ad/As, was $0.90 \pm 0.11$. The standard deviation of the latter is smaller than that of the former. Therefore, in the present study the Ad/As ratio, if shown, indicates the possible amplitude asymmetry.
The configuration of the cervical response, SEP-Cv7, was more complex than the one recorded at Erb's point. Often, but not always, the first negative deflection upwards had three tiny peaks whose latencies were about 9,11 , and $13 \mathrm{~ms}$; almost always the highest peak was the last one (L-N13) having an average latency of $12.4 \pm 0.6 \mathrm{~ms}$. The latency of the first maximal positive peak (P20) within the expected range was $20.2 \pm 2.5 \mathrm{~ms}$, while the peak-to-peak amplitude between $\mathrm{N} 13$ and P20 (A-N13/P20) was 4.5 \pm $1.1 \mu \mathrm{V}$, the corresponding Ad/As being $0.90 \pm$ 0.11 . The respective values for the ulnar nerve in control subjects were quite similar, but generally the latencies were to some extent longer than in the median nerve (Table 2). The difference was about $0.5-1.0 \mathrm{~ms}$. The motor conduction velocity of the ulnar nerve between the wrist and Erb's point was slower than that of the median nerve, the difference being about $5 \mathrm{~m} / \mathrm{s}$.

Table 2 shows the results of recordings of median nerve stimulation only in the 16 control subjects. The early positive component of SSEP,

Table 2 Somatosensory responses from the same trials as in Table 1. Stimulation of the median nerve at wrist; recording from the inion (NEP) and from the contralateral somatosensory area of the scalp (SSEP) Reference: mid-forehead $(F z)$ in NEP and the earlobe of stimulation side in SSEP. The latency measurements of somatosensory evoked responses up to the peak $N 30$ are also presented

\begin{tabular}{|c|c|c|c|c|c|c|c|c|c|}
\hline & \multicolumn{4}{|l|}{$N E P$} & \multicolumn{5}{|l|}{ SSEP } \\
\hline & $\begin{array}{l}L-N 14 \\
(m s)\end{array}$ & $\begin{array}{l}L-P 25 \\
(m s)\end{array}$ & $\begin{array}{l}A-N 14 / P 25 \\
(\mu V)\end{array}$ & $A d / A s$ & $\begin{array}{l}L-P 25 \\
(m s)\end{array}$ & $\begin{array}{l}L-P 25 \\
(m s)\end{array}$ & $\begin{array}{l}L-N 30 \\
(m s)\end{array}$ & $\begin{array}{l}N 20 / P 25 \\
(\mu V)\end{array}$ & $\begin{array}{l}A-P 25 / N 30 \\
(\mu V)\end{array}$ \\
\hline $\begin{array}{l}\text { Mean } \\
\text { SD } \\
\text { N }\end{array}$ & $\begin{array}{c}13.0 \\
0.8 \\
16\end{array}$ & $\begin{array}{c}21.5 \\
1.5 \\
16\end{array}$ & $\begin{array}{l}3.5 \\
1.3 \\
16\end{array}$ & $\begin{array}{c}0.98 \\
0.18 \\
16\end{array}$ & $\begin{array}{c}18.0 \\
1.0 \\
16\end{array}$ & $\begin{array}{c}22.0 \\
2.6 \\
16\end{array}$ & $\begin{array}{c}29.7 \\
5.0 \\
16\end{array}$ & $\begin{array}{c}2.5 \\
1.3 \\
16\end{array}$ & $\begin{array}{l}3.2 \\
1.6 \\
16\end{array}$ \\
\hline
\end{tabular}


P15 studied by Sances et al. (1978), Nakanishi et al. (1978) and others, was seen in almost every recording. This component, however, was not used because there seemed to be too much variability in its configuration and amplitude. The average latency of the peak of N20 (L-N20) was $18.0 \pm 1.0 \mathrm{~ms}$, and the latency of the peak P25 (L-P25) was $22.0 \pm 2.6 \mathrm{~ms}$. The respective values of NEP were: L-N14 was $13.0 \pm 0.8 \mathrm{~ms}$ and L-P25 was $21.5 \pm 1.5 \mathrm{~ms}$.

The amplitude between peaks $\mathrm{N} 20$ and P25 (A-N20/P25) was $2.5 \pm 1.3 \mu \mathrm{V}$ and A-P25/N30 was $3.2 \pm 1.6 \mu \mathrm{V}$; the amplitude between nuchal responses $\mathrm{N} 14$ and $\mathrm{P} 25$ (A-N14/P25) was 3.5士 $1.3 \mu \mathrm{V}$.

The standard deviations of the peaks N13, N14, $\mathrm{N} 20$, and of the latencies and conduction velocities to the brachial plexus were relatively low-under $10 \%$ of the respective mean. The standard deviation of the ratio Ad/As was usually more limited than that of the absolute amplitudes $(10-20 \%$ and about $20-60 \%$ respectively of the mean), even though this ratio of A-N20/P25 from the scalp was about $40 \%$ of the corresponding mean and therefore not tabulated).

Table 3 shows the latency differences between peaks N20 and N14 (latency difference N20-N14) when the median nerve was stimulated, and differences between the peak N13 of SEP-Cv7 and the action potential at Erb's point (latency difference N13-P1) when both median and ulnar nerves were stimulated. The latency difference N20-N14 was $5.1 \pm 0.8 \mathrm{~ms}$, and latency difference N13-P1 of median nerve was $4.2 \pm 0.5 \mathrm{~ms}$. The latency difference N13-P1 of ulnar nerve was $4.7 \pm 0.6 \mathrm{~ms}$.

\section{PATIENTS}

Case 1

A 29 year old woman (LP), with cubital syndrome of the ulnar nerve of her right arm had a neurosurgical anteposition operation after she had been suffering for 10 months. Postoperatively she

Table 3 Median nerve stimulation at the wrist. Latency difference (N20-N14) of the peak N20 of SSEP from the peak of N14 of NEP. Latency difference (N13-P1) of the peak N13 of SEP-CV7 from the beginning of the action potential at Erb's point $(P l B r-A P)$

\begin{tabular}{lccl}
\hline & $\begin{array}{l}\text { Median nerve latency difference } \\
\text { N20-N14 }(\mathrm{ms})\end{array}$ & $\begin{array}{l}\text { Ulnar nerve } \\
\text { latency } \\
\text { difference } \\
\text { N13-Pl }(\mathrm{ms})\end{array}$ \\
\hline Mean & 5.0 & 4.2 & 4.7 \\
SD & 0.8 & 0.5 & 0.6 \\
N & 16 & 10 & 10 \\
\hline
\end{tabular}

$5 \mu \mathrm{V}$

$\overline{10 \mathrm{~ms}}$
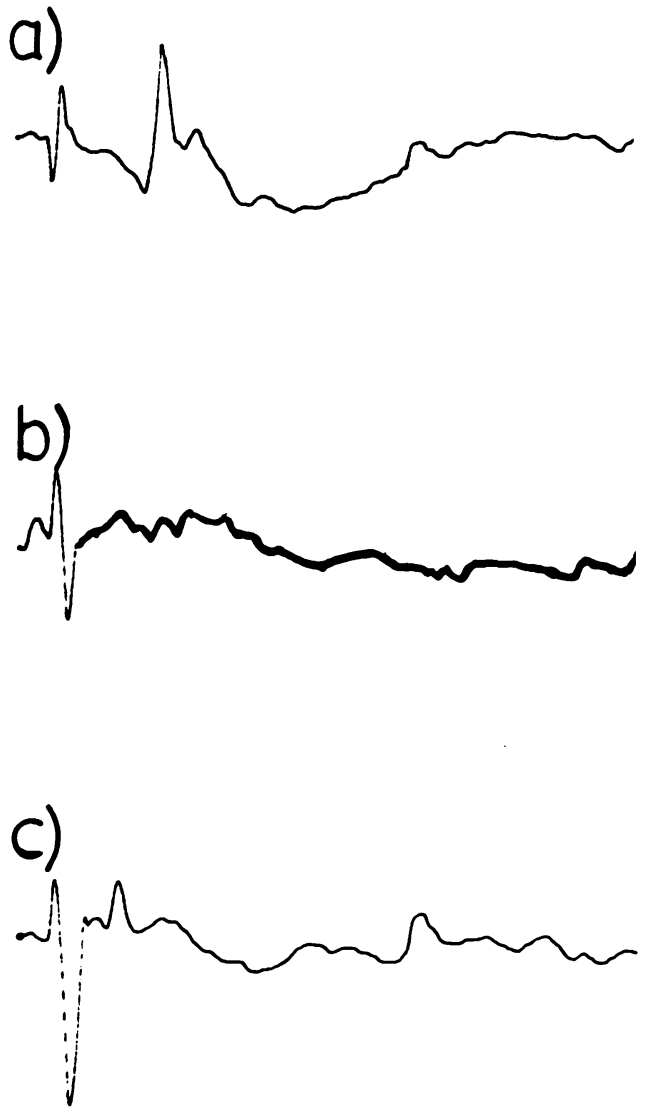

Fig. 2 Somatosensory evoked responses recorded at Erb's point evoked by median nerve stimulation at the wrist (a), by right ulnar nerve stimulation also at the wrist $(b)$, and by right ulnar nerve stimulation above the elbow (c) in case 1 with ulnar sulcus entrapment neuropathy.

developed a partial hypothenar atrophy and weakness of abduction of the right little finger.

Stimulation of the right ulnar nerve at the wrist induced no response at Erb's point (Fig. 2). Stimulation of the same nerve at the elbow above the ulnar sulcus induced a low amplitude but definite action potential at Erb's point (Fig. 2c). Stimulation of the median nerve of the same side, and both nerves contralaterally, revealed normal conduction latencies and velocities between the wrist and Erb's point (Fig. 2a, Fig. 3a, b). Conduction velocity of both ulnar nerves between the elbow and Erb's point was $65 \mathrm{~m} / \mathrm{s}$ (Figs. $2 \mathrm{c}$ and $3 c)$ and was within normal limits. These findings 

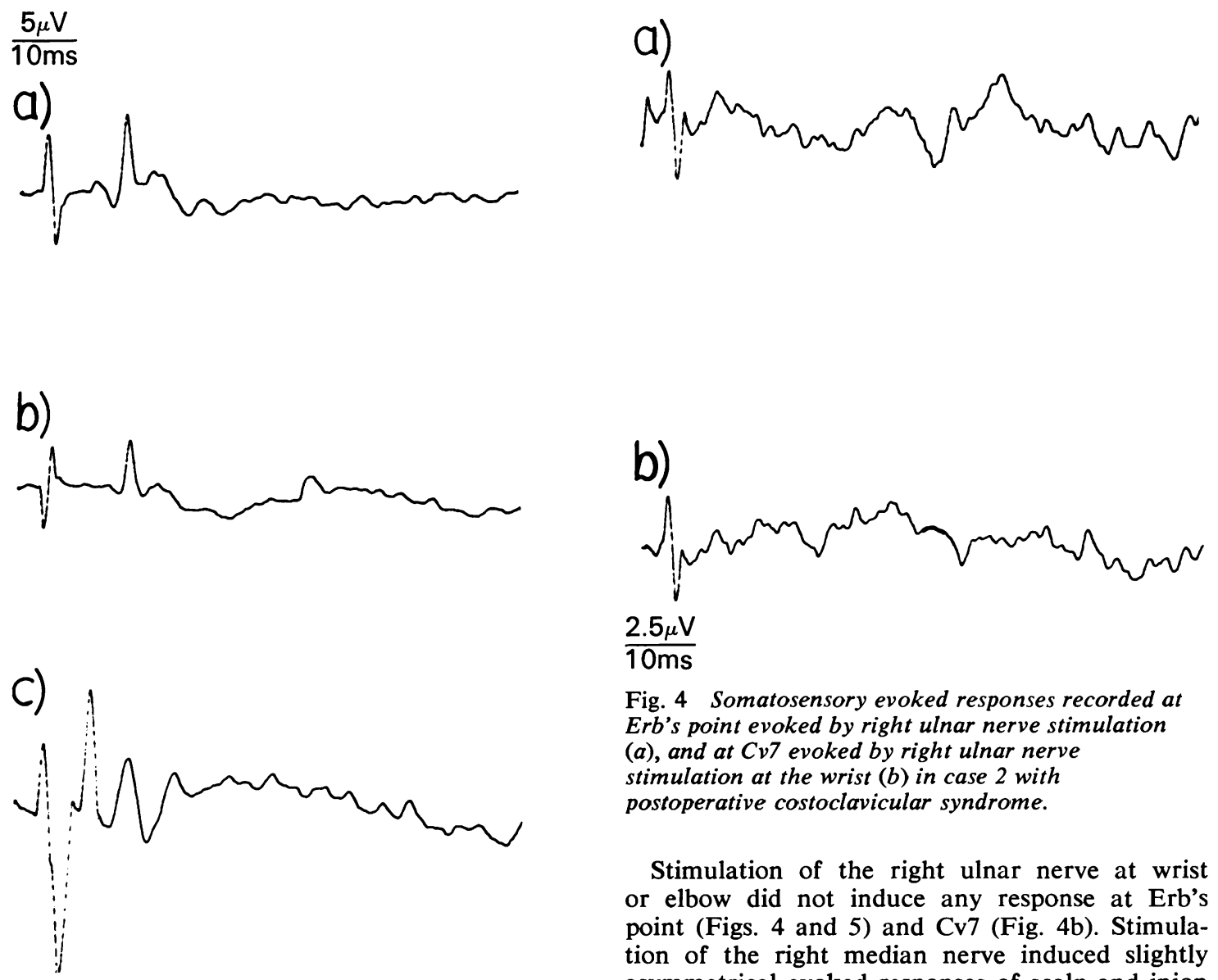

$\frac{2.5 \mu \mathrm{V}}{10 \mathrm{~ms}}$

Fig. 4 Somatosensory evoked responses recorded at Erb's point evoked by right ulnar nerve stimulation (a), and at $C v 7$ evoked by right ulnar nerve stimulation at the wrist $(b)$ in case 2 with postoperative costoclavicular syndrome.

Stimulation of the right ulnar nerve at wrist or elbow did not induce any response at Erb's point (Figs. 4 and 5) and Cv7 (Fig. 4b). Stimulation of the right median nerve induced slightly asymmetrical evoked responses of scalp and inion

Fig. 3 Somatosensory evoked responses recorded at Erb's point evoked by left median nerve stimulation $(a)$, by left ulnar nerve stimulation at the wrist $(b)$, and by left ulnar nerve stimulation above the elbow (c) in case 1 .

suggest that the main lesion site was in the right elbow area, probably in the ulnar sulcus.

\section{Case 2}

A 47 year old woman (ML) had suffered from bronchial asthma for many years. She had had symptoms in the right upper limb for six months, viz., muscular weakness of the hand, especially in the hypothenar and thenar areas. The diagnosis of costoclavicular syndrome was made. Resection of the first rib was carried out to widen the right thoracic outlet. The patient made a partial recovery. There was partial return of muscle power of the little finger and of sensation to pain stimuli. Some muscular atrophy of the hypothenar eminence, however, remained. when compared to those of left hand stimulation. The results agreed with clinical findings pointing to a brachial plexus compression which had caused a partial but irreversible lesion.

Case 3

A 52 year old woman (VP) had been showing signs of multiple sclerosis for eight years-variable weakness and clumsiness of the lower limbs and left upper limb and optic neuritis. The diagnosis of multiple sclerosis had also been confirmed by visual evoked responses and by changes in the CSF. She was investigated primarily as a case showing conductive lesions within the CNS.

The median nerve was stimulated at the wrist and the evoked responses were recorded at the four different levels described earlier. Registration at Erb's point and $\mathrm{Cv} 7$ gave values within normal limits, but L-N20 were pathologically increased (Fig. 6), especially when the left median nerve was stimulated (L-N14 was $23 \mathrm{~ms}$ and 
L-N20 was about $32 \mathrm{~ms}$ ) (Fig. 6c. d). Thus, slowing of somatosensory nerve impulses was clearly central and not peripheral.

\section{Case 4}

A 45 year old man (VS), with acute facial nerve paresis on the left, had aphasia and weakness and sensory impairment of the left upper ex-

$\frac{2.5 \mu \mathrm{V}}{10 \mathrm{~ms}}$
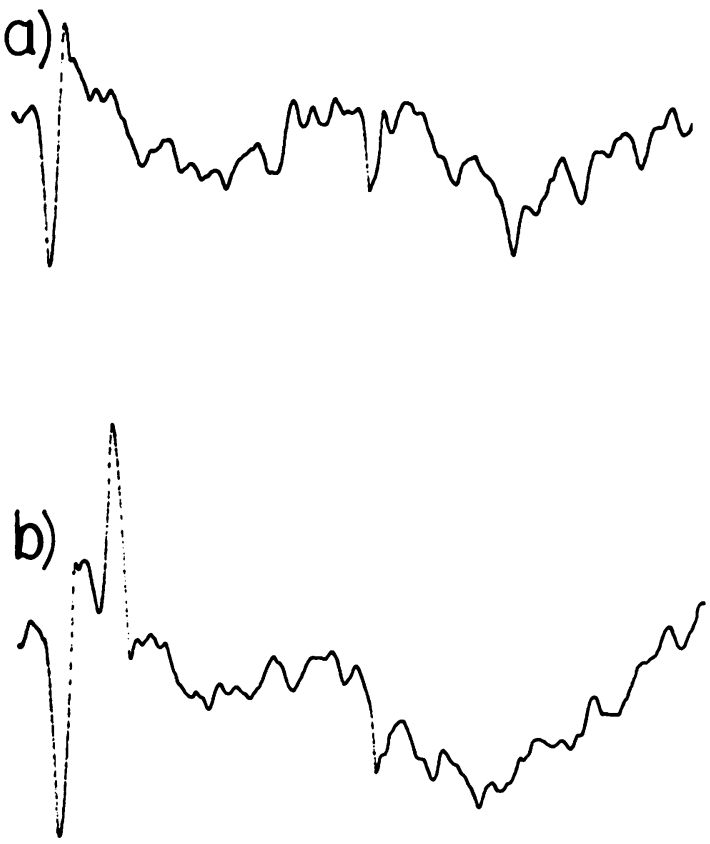

Fig. 5 Somatosensory evoked responses recorded at Erb's point evoked by right ulnar nerve stimulation above the elbow (a) and by left ulnar nerve stimulation above the elbow (b) in case 2.

tremity.. Carotid angiography, brain scanning, and computer tomography of the brain confirmed the presence of a malignant tumour in the right temporal lobe.

Peripheral neurography of the upper limbs was normal and stimulation of the right median nerve induced normal evoked responses at the scalp and inion (Fig. 7). However, stimulation of the left median nerve did not cause any noticeable evoked responses in the scalp recording (Fig. 8), while inion recording gave normal responses. All the other recordings at lower levels gave values within normal limits.
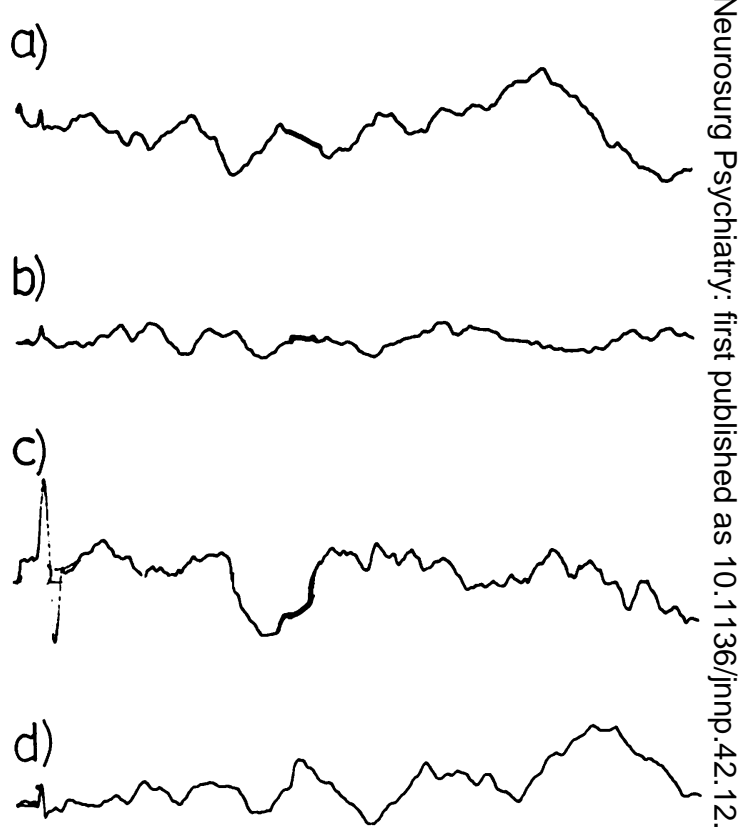

$2.5 \mu \mathrm{V}$

$10 \mathrm{~ms}$

Fig. 6 Somatosensory evoked responses recorded at the inion, evoked by right median nerve stimulation at the wrist (a), and at the scalp (b) in the patient (case 3) with multiple sclerosis.

\section{Discussion}

Conventional electroneuromyographic techniques are less reliable for lesions above the axilla buto the somatosensory evoked cortical response affords a real improvement in neurodiagnostico localisation. However, there are also complexo structures between the peripheral nerve and cere- $\subseteq$ bral cortex which must be examined. In the $\vec{\circ}$ present study we investigated the potentials evoked 3 by stimulating the median and ulnar nerves at the wrist, the registration sites being at Erb's? point, the seventh cervical spine, and the scalp.

In healthy subjects the conduction time of the median nerve from wrist to brachial plexus (Erb'sopoint) was $8.2 \mathrm{~ms}$ (conduction velocity $71 \mathrm{~m} / \mathrm{s}$ ), which is in the range reported by Jones (1977) and El-Negamy and Sedgwick (1978). The latency? from wrist to Cv7 (L-N13) in the same nerve waso $12.4 \mathrm{~ms}$, which is also close to the values reported by Jones (1977). The mean latency to the nexto proximal level (L-N14) was $13.0 \mathrm{~ms}$, and to the scalp (L-N20) $18.0 \mathrm{~ms}$. These values are slightlyo lower than those of Cracco (1973), Jones (1977), N 


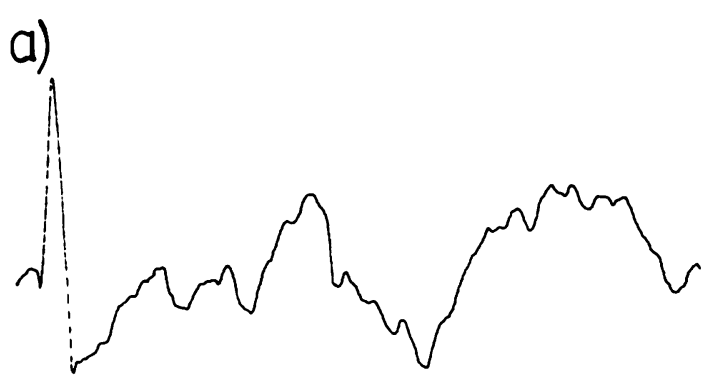

b)

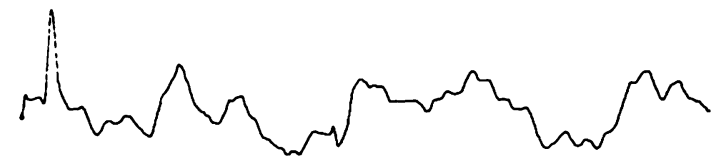

$2.5 \mu \mathrm{V}$

$10 \mathrm{~ms}$

Fig. 7 Somatosensory evoked responses recorded at the scalp (C3) by stimulation of the right median nerve at the wrist $(a)$ and at the inion evoked by the same stimulation (b) in the patient (case 4) with a right temporal brain tumour.

and Hume and Cant (1978), but the differences are not significant (less than $2 \mathrm{SD}$ ). The latencies of the ulnar nerve responses were somewhat longer than those for median nerve, as also found by Koivikko et al. (1976). The distribution of the values of measured latencies, L-P1, L-N13, L-N14, and L-N20, was in a narrow range (SD less than $10 \%$ of the mean), suggesting that the method is suitable for clinical use. The ratios of amplitudes from the right and left side (Ad/As) proved better for showing amplitude asymmetry than the absolute values of amplitudes, the standard deviations of the former being only about a half of the latter values. From the clinical point of view, the differences between the various latencies for different levels are important (Table 2). The latency difference N20-N14 may have clinical importance in the evaluation of the conduction of the central somatosensory pathway, as suggested by Hume and Cant (1978), while the latency difference N13-Pl may be of value in pathological conditions of cervical roots and proximal parts of the brachial plexus. Case 2 (ML) may serve as an example here. She had a clinically evident costoclavicular syndrome on the right side, and no response at

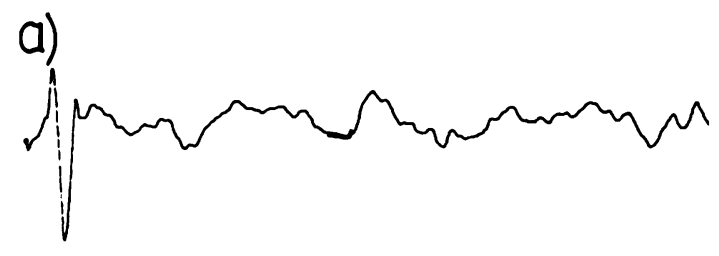

b)

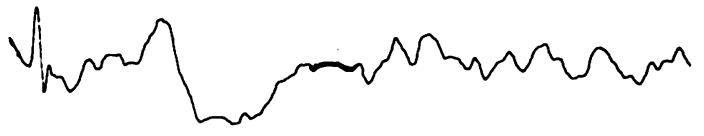

$\frac{2.5 \mu \mathrm{V}}{10 \mathrm{~ms}}$

Fig. 8 Somatosensory evoked responses recorded at the scalp (C4) evoked by left median nerve stimulation at the wrist (a) and the corresponding responses at the inion evoked by the same stimulation (b) in case 4.

Erb's point could be obtained on ulnar nerve stimulation at the wrist and elbow (Fig. 4). Nevertheless, median nerve stimulation induced clear responses at the level of the brachial plexus and above it, suggesting that the lesion was located in the medial part of the brachial plexus.

Case 3 (VP) had clinical signs of motor impairment in the left upper limb as a result of multiple sclerosis. The latencies to the peaks N14 and N20 were markedly prolonged, while the latencies to Erb's point and Cv7 were within normal limits (Fig. 6). The latency difference, N20-N14, especially when the left median nerve was stimulated, was also markedly prolonged (about 4-5 SD above the mean). The findings suggest the presence of lesions in cerebral structures, but not peripheral to Cv7. The decreased conduction times of the central somatosensory pathways in multiple sclerosis have been reported by many investigators (Small et al., 1978 and others).

Case 4 (VS) with a right temporal lobe tumour is also of interest. No response could be obtained from the scalp on the right, other latencies and amplitudes being in normal ranges, suggesting that the lesion was quite near the cortex. Some investigators have suggested that the peak N20 originates from the cortex and peak N14 from 
the brainstem, perhaps from dorsal column nuclei (Hume and Cant, 1978) and perhaps also from the cerebellum (Koivikko, 1975). In our case the thalamocortical pathways would appear to be the most probable site of the conduction block caused by the temporal lobe tumour.

Routine electroneuromyography usually provides adequate information for clinical localisation of nerve lesions below the brachial plexus. Diagnostic difficulties usually arise with more proximal lesions. The method presented in the study provides complementary information towards solving these problems. Wider application of the techniques may allow still better localisation of pathological conditions of the nervous system.

\section{References}

Cracco, R. Q. (1973). Spinal evoked response: peripheral nerve stimulation in man. Electroencephalography and Clinical Neurophysiology, 35, 379386.

Donchin, E., Callaway, E., Cooper, R., Desmedt, J. E., Goff, W. R., Hillyard S. A., and Sutton, S. (1977). Publication criteria for studies of evoked potentials (EP) in man. Report of a Committee. In Attention, Voluntary Contraction and Eventrelated Cerebral Potentials, pp. 1-11. Edited by J. E. Desmedt. Karger: Basel.

El-Negamy, E., and Sedgwick, E. M. (1978). Properties of a spinal somatosensory evoked potential recorded in man. Journal of Neurology, Neurosurgery, and Psychiatry, 41, 762-768.

Ertekin, C. (1976). Studies on the human evoked electrospinogram. Acta Neurologica Scandinavica, 53, 21-38.

Ertekin, C. (1978). Comparison of the human evoked electrospinogram recorded from the intrathecal, epidural and cutaneous levels. Electroencepha lography and Clinical Neurophysiology, 44, 683-690.0

Hume, A. L., and Cant, B. R. (1978). Conduction time in central somatosensory pathways in man. Electro encephalography and Clinical Neurophysiology, 45 361-375.

Jones, S. J. (1977). Short latency potentials recordef. from the neck and scalp following median nerve stimulation in man. Electroencephalography and Clinical Neurophysiology, 43, 853-863.

Koivikko, M. (1975). Some characteristics of the nuchal evoked potential. Annales Universitatis Turkuensis, series D, medica 4.

Koivikko, M. J., Lang, A. H., and Falck, B. (1976) Diagnostic possibilities for the nuchal evoked potential. Acta Neurologica Scandinavica, 54, 192음 199.

Nakanishi, T., Shimada, Y., Sakuta, M., an\$ Tokpkura, Y. (1978). The initial positive com: ponent of the scalp-recorded somatosensory evoked potential in normal subjects and in patients with? neurological disorders. Electroencephalography and Clinical Neurophysiology, 45, 26-34.

Sances, A., Larson, S. J., Cisick, J. F., Myklebust, J. Ewing, C. L., Jodat, R., Ackmann, J. J., and Walsh; P. (1978). Early somatosensory evoked potentials? Electroencephalography and Clinical Neum $\vec{F}$ physiology, 45, 505-514.

Shimoji, K., Higashi, H., and Kano, T. (1971). Ep E dural recording of spinal electrogram in mgn? Electroencephalography and Clinical Neur physiology, 30, 236-239.

Shimoji, K., Kano, T., Higashi, H., Morioka, ठి.థ and Henschel, E. O. (1972). Evoked spinal electo grams recorded from epidural space in man. Jour of Applied Physiology, 33, 468-471.

Small, D. G., Matthews, W. B., and Small, M. (1978) The cervical somatosensory evoked potentialo (SEP) in the diagnosis of multiple sclerosis. Journal of the Neurological Sciences, 35, 211-224. 